\title{
Effect of membrane property modulations by dopamine on synchronous/asynchronous activity in a network of globus pallidus externus
}

\author{
Katsunori Kitano*1, Tomohiro Fujita ${ }^{2}$ and Tomoki Fukai ${ }^{3}$
}

Address: ${ }^{1}$ Department of Human and Computer Intelligence, Ritsumeikan University, Kusatsu, Shiga 525-8577, Japan, ${ }^{2}$ Graduate School of Science and Engineering, Ritsumeikan University, Kusatsu, Shiga 525-8577, Japan and ${ }^{3}$ Brain Science Institute, RIKEN, Wako, Saitama 351-0198, Japan

Email: Katsunori Kitano* - kitano@ci.ritsumei.ac.jp

* Corresponding author

from Seventeenth Annual Computational Neuroscience Meeting: CNS*2008

Portland, OR, USA. 19-24 July 2008

Published: II July 2008

BMC Neuroscience 2008, 9(SuppI I):P56 doi:10.1 I86/I47I-2202-9-SI-P56

This abstract is available from: http://www.biomedcentral.com/I47I-2202/9/SI/P56

(C) 2008 Kitano et al; licensee BioMed Central Ltd.

\section{Introduction}

Subthalamic nuclei (STN) and globus pallidus externus (GPe) are important nuclei for basal ganglia functions since spatio-temporal patterns of neural activity in the nuclei have a close relationship with movement disorders such as Parkinson disease. However, the mechanism of transition between normal tonic activity and pathological rhythmical burst activity with changing dopamine levels has been still unclear. Rebound burst activity of STN neurons, which is induced by strong hyperpolarization, may play a key role for such an activity mode transition. On the other hand, the GPe is a major source of hyperpolarizing input to the STN. Therefore, an understanding of the dynamical properties of a GPe network is gaining importance.

\section{Methods}

We investigated how synchronous/asynchronous properties of the GPe network were modulated by dopamine. To this end, we first constructed a single compartment model of a GPe neuron, and applied phase response analysis to the model GPe neuron [1], changing conductances of a persistent sodium channel and an L-type calcium channel, both of which are modulated by dopamine in the striatal spiny neurons [2].

\section{Results}

We examined two conditions; the condition of an identical input strength, under which the firing rate of the GPe neuron changed, and that of an identical firing rate, which was realized by adjusted input currents. Under both conditions, as both of the conductances increase (dopamine level was thought to be depleted), stable phase differences diminished, i.e., the synchronous activity came to be stable (Fig. 1). The results showed that the dopaminergic

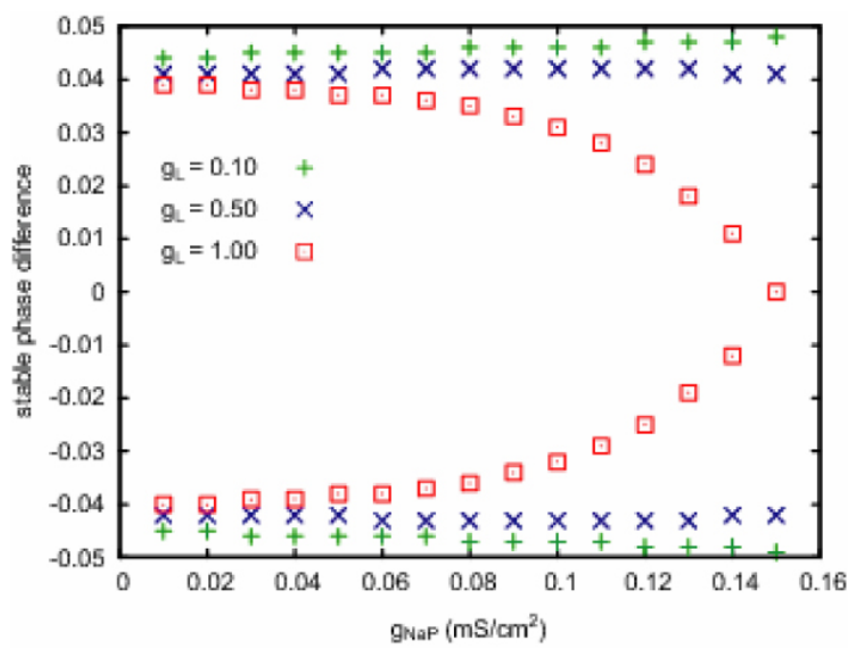

\section{Figure I}

Stable phase differences for various combinations of $\mathrm{gNaP}$ and $\mathrm{gL}$ under the condition of an identical period. When both $\mathrm{gNaP}$ and $\mathrm{gL}$ took large values, phase difference of 0 , i.e., the synchronous state, was stable. 
effect on intrinsic membrane property was one of the candidates to induce pathological burst activity in the STN.

\section{References}

I. Kuramoto Y: Chemical oscillations, waves, and turbulence NewYork: Springer-Verlag; 1984.

2. Surmeier DJ, Ding J, Day M, Wang Z, Shen W: DI and D2 dopamine-receptor modulation of striatal glutamatergic signaling in striatal medium spiny neurons. TRENDS in Neurosciences 2007, 30:228-234.

Publish with Bio Med Central and every scientist can read your work free of charge

"BioMed Central will be the most significant development for disseminating the results of biomedical research in our lifetime. " Sir Paul Nurse, Cancer Research UK

Your research papers will be:

- available free of charge to the entire biomedical community

- peer reviewed and published immediately upon acceptance

- cited in PubMed and archived on PubMed Central

- yours - you keep the copyright

Submit your manuscript here:

http://www.biomedcentral.com/info/publishing_adv.asp 